\title{
Impairments, disabilities and needs assessment among non-fatal war injuries in South Lebanon, Grapes of Wrath, 1996
}

\author{
Abla Mehio Sibai, Nadine Sameer Shaar, Samar El Yassir
}

\begin{abstract}
Study objective-To examine the impact of non-fatal war related injuries on physical disability in a group of war wounded civilians and to assess their needs.

Design-Cross sectional study. Home interviews were conducted using a structured interview schedule around one month after the injury, to assess impairments, disabilities, and needs.

Study population and setting-War wounded persons in towns and villages in South Lebanon during the attack "Grapes of Wrath" in 1996.

Results-The majority of the study population were young and in their productive age, mostly injured in the street or while hiding in open shelters. Around half of the injuries resulted in impairments, but, there were no age, gender or geographical differentials by severity of impairment. Almost one third $(29 \%)$ of the students enrolled in schools at the time of the injury reported failure to continue their education and $42 \%$ of the working members lost their jobs with no potential for $34 \%$ of them to resume their former jobs. The impact of the injury on impairments, motor disabilities and physical independence was highest for injuries to the lower limbs (age and sex adjusted risk ratio (RR) $1.62,95 \%$ confidence intervals (CI) 1.25 , $2.10 ; 2.98,95 \%$ CI 2.09, 4.23; and $2.13,95 \%$ CI $1.39,3.27$, respectively). Despite the acute and early relief services provided by all those concerned at the time of the injury, when asked about unmet needs, the majority of the impaired $(66 \%)$ reported the need for additional services, mostly medical in nature. The degree of disability was a salient factor for the need for rehabilitative services but not for medical services.
\end{abstract}

American University of Beirut, Faculty of Health Sciences, Beirut, Lebanon A Mehio Sibai

IMPACT-Eastern Mediterranean Region, Beirut, Lebanon N Sameer Shaar S El Yassir

Correspondence to: Dr A Mehio Sibai

Accepted for publication 5 June 1999 cally, most research on wars focused on battlefield casualties among military personnel and on the acute destruction of physical infrastructure for purposes of military planning. More recently, however, particularly since the second world war, data have been extended to study the effects of warfare on morbidity and mortality among the civilian population. ${ }^{1}$ War impacts on health in a variety of ways, ranging from direct injuries and deaths to indirect effects such as population displacements, decline in social services and disruption of medical and public health programmes..$^{2-4}$ The chronic disabilities resulting from morbidity and injuries among the victims of wars remain the single most daunting task for the families of the injured, their communities and the society as a whole. When assistance is provided to these victims, it is usually for a short period of time immediately after the injury. This leads to deterioration of the disability, reduced work productivity and further burdens a society already facing social disruptions and economic deterioration.

After 16 years of civil wars and foreign intrusions (1975-1991), Lebanon represents a country struggling through rehabilitation and recovery. The country is in the process of re-building its ruined physical infrastructure while tackling the challenges of social reconstruction and human development. Unfortunately, however, in April 1996, a major setback occurred when hostilities erupted between Israel and Hizbullah, a warring faction in the South. Grapes of Wrath, the attack on Southern Lebanon, resulted in considerable material and human losses: 36 villages were attacked and around 22 were damaged substantially. It was estimated that on one single day, the 18 of April, more than 100 died during heavy artillery attacks at a United Nations base near the small village of Qana. United Nations Forces in Lebanon (UNIFIL) estimated the total human loss during the 16 day attack at 162 dead and 338 injured people. The National High Relief Committee also gave similar figures (160 dead and 340 injured). A survey was planned and conducted by IMPACT/Eastern Mediterranean Region to study the incidence of disability among the injured and to tackle their needs. More specifically, the survey was set out to examine the demographic characteristics of the injured, to assess the incidence of impairment and types and levels of disability associated with the injury, to review services offered, and, finally to evaluate the injured needs. 


\section{Methods}

The study was carried out in May 1996, about one month after the end of the attack. The study population included persons who had non-fatal war-related injuries whether the injury resulted in impairments/disabilities or not. The list of the names of injured people and the villages they come from was compiled from different sources mostly from the concerned non-governmental organisations. These included mainly, among others, the Charitable Organization for the Help of Injured and Disabled Persons by War (Al-Jarha Foundation) and the Secour Populaire Libanais. The list was validated for reliability and completeness with lists from other sources and through confirmation by local authorities and hospitals in the community. Originally, the list included the names of 334 injured people, however, nine were later added after complete enumeration of all injured persons $(n=343)$.

The interview schedule included five main sections: basic sociodemographic characteristics, circumstances of the injury (the place and date of injury and body part affected), associated impairments and disabilities in accordance with the WHO definitions and classifications, ${ }^{5}$ the impact of the injury on social roles (schooling and work), and finally, medical services received and needs assessment. The severity of the impairment was categorised as either temporary or long term depending on expected chronicity. Those whose condition had been medically diagnosed and was expected to prevail for a relatively limited period of time (from 1 to 24 months) were classified as having temporary impairment; while those whose condition was not expected to improve within the defined period were clas-

Table 1 Distribution of injured population by demographic characteristics, circumstances of injury and associated impairments and disabilities in men and women, Grapes of Wrath, Lebanon, 1996

\begin{tabular}{|c|c|c|c|c|c|c|}
\hline & \multicolumn{2}{|c|}{$\operatorname{Men}(n=176)$} & \multicolumn{2}{|c|}{ Women $(n=106)$} & \multicolumn{2}{|c|}{ Total $(n=282)$} \\
\hline & Number & $\%$ & Number & $\%$ & Number & $\%$ \\
\hline Age (mean (SD)) & \multicolumn{2}{|c|}{$27.5(15.3)$} & \multicolumn{2}{|c|}{$31.3(21.6)$} & \multicolumn{2}{|c|}{$28.9(18.0)$} \\
\hline \multicolumn{7}{|l|}{ Marital status } \\
\hline Single & 89 & 50.6 & 51 & 48.1 & 140 & 49.7 \\
\hline Married & 81 & 46.0 & 43 & 40.6 & 124 & 44.0 \\
\hline Widowed/separated & 6 & 3.4 & 12 & 11.3 & 18 & 6.4 \\
\hline Economic activity (\% working) & 108 & 61.4 & 5 & 4.7 & 113 & 40.1 \\
\hline \multicolumn{7}{|l|}{ Date of injury } \\
\hline On the 18 of April & 58 & 33.0 & 52 & 49.1 & 110 & 39.0 \\
\hline On other days & 118 & 67.0 & 54 & 50.9 & 172 & 61.0 \\
\hline \multicolumn{7}{|l|}{ Place of injury } \\
\hline Home & 30 & 17.0 & 26 & 24.5 & 56 & 19.9 \\
\hline Street & 80 & 45.5 & 25 & 23.6 & 105 & 37.2 \\
\hline Open shelter (UN base) & 53 & 30.1 & 50 & 47.2 & 103 & 36.5 \\
\hline Underground shelter & 13 & 7.4 & 5 & 4.7 & 18 & 6.4 \\
\hline Impairments (any) & 87 & 49.4 & 42 & 39.6 & 129 & 45.7 \\
\hline Permanent ( $\%$ among impaired) & 38 & 43.7 & 23 & 54.8 & 61 & 47.3 \\
\hline Disability (any) & 73 & 41.5 & 42 & 39.6 & 115 & 40.8 \\
\hline Personal independence (any) & 35 & 19.9 & 36 & 34.0 & 71 & 25.2 \\
\hline Eating/drinking & 2 & 1.1 & 8 & 7.6 & 10 & 3.6 \\
\hline Bathing & 20 & 11.4 & 17 & 16.0 & 37 & 13.1 \\
\hline Dressing & 28 & 15.9 & 22 & 20.8 & 50 & 17.7 \\
\hline Using toilet & 24 & 13.6 & 22 & 20.8 & 46 & 16.3 \\
\hline Housekeeping & 19 & 10.8 & 24 & 22.6 & 43 & 15.2 \\
\hline Motor disabilities (any) & 71 & 40.3 & 36 & 34.0 & 107 & 37.9 \\
\hline Locomotion & 70 & 39.8 & 36 & 34.0 & 106 & 37.6 \\
\hline Lifting/carrying & 6 & 3.4 & 0 & 0.0 & 6 & 2.1 \\
\hline \multicolumn{7}{|l|}{ Social roles } \\
\hline Inability to resume schooling ${ }^{\star}$ & 7 & 22.6 & 9 & 37.5 & 16 & 29.1 \\
\hline Inability to resume workt & 44 & 40.7 & 3 & 60.0 & 47 & 41.6 \\
\hline
\end{tabular}

*Among those who were enrolled in schools $(n=55)$. †Among those who were economically active before the injury $(\mathrm{n}=113)$. sified as having long term or permanent impairment. Disabilities were assessed in two major areas: personal self care (such as dressing, bathing, eating and included housekeeping) and motor disabilities (locomotion and lifting/carrying). The degree of disability was assessed depending on the number of positive responses to each item within the disability interview schedule.

A trained team of interviewers visited the targeted villages and interviewed the injured people or their proxies. Out of the 343 injured persons approached, $61(17.8 \%)$ could not be interviewed. These included mostly people $(\mathrm{n}=45,13.1 \%)$ who could not be traced: their injuries were mild and were treated as outpatients and/or there was no record of their specific addresses; seven ( $2 \%$ ) who died later as a result of their injuries; and an additional seven people $(2 \%)$ who resided in villages under the Israeli occupation and, hence, could not be approached. Only two refused to be interviewed. Field workers were instructed to conduct the interview with the injured themselves, whenever possible. However, this was not feasible in the majority of cases (55\%). A high proportion of these proxy interviews $(45 \%)$ was done on behalf of persons who were severely disabled and/or were not ready to talk about their condition. The remaining proxy interviews were conducted with parents on behalf of children who were below 15 years of age $(25 \%)$, or because the injured was not at home at the time of the survey (18\%), and $12 \%$ were done on behalf of those who were still in the hospital at the time of data collection. The proxies were mainly the carers and/or close relatives of the injured, such as parents $(34.4 \%)$, siblings $(29.3 \%)$, spouses $(11.5 \%)$ and sons or daughters $(5.7 \%)$.

Descriptive statistics presenting the distribution of injuries, impairments and disabilities were computed for men and women separately. Risks and risk ratios adjusted for sex and age and their $95 \%$ confidence intervals were calculated to estimate the association between body part affected with impairments and disabilities. Age included in the regression analysis was grouped in three categories (0-14 years, 15-59 years and 60 years and over). Analysis was conducted using STATA statistical package for Windows, release $4.0 .^{6}$

\section{Results}

The interviewed study population comprised a total of 282 injured persons, mostly male $(62 \%)$. Their age ranged from as young as newborns to 93 years old with a mean of 27.5 $(\mathrm{SD})=15.3$ years $)$ and $31.3(\mathrm{SD}=21.6$ years $)$ for males and females respectively. The highest proportion of injured people $(73 \%)$ was in their productive age (15-59 years).

Table 1 presents a comparison between the male and female population with regard to demographic characteristics, circumstances of injury and associated impairments and disabilities. The injured were mostly single $(49.7 \%)$ or married $(44.0 \%)$. Among men, the majority $(61.4 \%)$ reported that they had been working before the attack, with an average 
Table 2 Association between site of injury with impairments, motor disabilities and physical independence: risk, risk ratios and 95\% confidence intervals (CI), Grapes of Wrath, Lebanon, 1996

\begin{tabular}{|c|c|c|c|c|c|c|c|c|c|}
\hline \multirow{2}{*}{$\begin{array}{l}\text { Site of } \\
\text { injury }\end{array}$} & \multicolumn{3}{|c|}{ Impairments } & \multicolumn{3}{|c|}{ Motor disabilities } & \multicolumn{3}{|c|}{ Personal independence } \\
\hline & $\%$ & $R R t$ & $95 \% C I$ & $\%$ & $R R+$ & $95 \% C I$ & $\%$ & $R R+$ & $95 \% C I$ \\
\hline \multicolumn{10}{|l|}{ Head } \\
\hline No & 45.1 & 1.0 & & 38.7 & 1.0 & & 24.8 & 1.0 & \\
\hline Yes & 48.3 & 1.11 & $0.82,1.50$ & 35.0 & 0.95 & $0.64,1.41$ & 26.7 & 1.13 & $0.70,1.83$ \\
\hline \multicolumn{10}{|l|}{ Face } \\
\hline No & 42.7 & 1.0 & & 39.7 & 1.0 & & 24.6 & 1.0 & \\
\hline Yes & 60.0 & 1.45 & $1.11,1.89^{\star}$ & 30.0 & 0.80 & $0.51,1.25$ & 28.0 & 1.30 & $0.81,2.08$ \\
\hline \multicolumn{10}{|l|}{ Chest } \\
\hline No & 45.7 & 1.0 & & 37.5 & 1.0 & & 24.6 & 1.0 & \\
\hline Yes & 46.2 & 1.02 & $0.67,1.57$ & 42.3 & 1.11 & $0.70,1.75$ & 30.8 & 1.22 & $0.68,2.20$ \\
\hline \multicolumn{10}{|c|}{ Abdomen } \\
\hline No & 45.5 & 1.0 & & 37.2 & 1.0 & & 23.7 & 1.0 & \\
\hline Yes & 50.0 & 1.18 & $0.71,1.97$ & 50.0 & 1.41 & $0.87,2.29$ & 50.0 & 1.88 & $1.11,3.15^{\star}$ \\
\hline \multicolumn{10}{|c|}{ Upper limbs } \\
\hline No & 45.3 & 1.0 & & 35.4 & 1.0 & & 25.5 & 1.0 & \\
\hline Yes & 46.7 & 1.01 & $0.77,1.32$ & 43.3 & 1.18 & $0.88,1.59$ & 24.4 & 0.92 & $0.60,1.40$ \\
\hline \multicolumn{10}{|c|}{ Lower limbs } \\
\hline No & 35.1 & 1.0 & & 20.1 & 1.0 & & 17.5 & 1.0 & \\
\hline Yes & 58.6 & 1.62 & $1.25,2.10^{\star}$ & 59.4 & 2.98 & $2.09,4.23^{\star}$ & 34.4 & 2.13 & $1.39,3.27^{\star}$ \\
\hline \multicolumn{10}{|c|}{ Back/spine } \\
\hline No & 46.4 & 1.0 & & 37.2 & 1.0 & & 24.0 & 1.0 & \\
\hline Yes & 40.6 & 0.85 & $0.55,1.32$ & 43.8 & 1.15 & $0.75,1.75$ & 34.4 & 1.42 & $0.85,2.36$ \\
\hline \multicolumn{10}{|c|}{ Shrapnels all over body } \\
\hline No & 46.4 & 1.0 & & 39.5 & 1.0 & & 25.7 & 1.0 & \\
\hline Yes & 38.1 & 0.82 & $0.46,1.43$ & 19.1 & 0.47 & $0.20,1.15$ & 19.1 & 0.71 & $0.29,1.77$ \\
\hline
\end{tabular}

${ }^{\star} \mathrm{p}$ Value $<0.05 .+$ Risk ratio adjusted for sex and age.

monthly income of LL 460000 , which is equivalent to $\$ 300$. The largest number of injuries (39\%) occurred on the 18 of April, near the village of Qana, with females being at higher risk of exposure, on that specific day, than males. The majority of the injuries occurred either in the streets $(37.2 \%)$ or at the UN base near Qana village (36.5\%).

Almost half of the injuries among our study population resulted in impairments $(45.7 \%)$, and these were equally distributed between temporary and permanent impairments (table $1)$. The majority of the impaired reported a single impairment $(77.5 \%)$, however, the proportion reporting multiple impairments was much higher among those who acquired permanent $(41 \%)$ than temporary (6\%) impairments (data not shown). Because the most common site of injuries was injuries to the lower limbs $(45.4 \%)$, the impact of the injury

Table 3 Unmet need by selected baseline variables among injured study population, Grapes of Wrath, Lebanon, 1996

\begin{tabular}{|c|c|c|c|c|}
\hline & \multicolumn{4}{|c|}{ Unmet need for } \\
\hline & \multicolumn{2}{|c|}{ Medical services } & \multicolumn{2}{|c|}{ Rehabilitative services } \\
\hline & $\%$ & p value & $\%$ & $p$ value \\
\hline Total & 26.6 & & 16.0 & \\
\hline \multicolumn{5}{|l|}{ Sex } \\
\hline Male & 29.0 & & 17.1 & \\
\hline Female & 22.6 & 0.243 & 14.2 & 0.520 \\
\hline \multicolumn{5}{|l|}{ Age groups (y) } \\
\hline $0-14$ & 14.0 & & 6.0 & \\
\hline $15-59$ & 29.1 & & 16.5 & \\
\hline $60+$ & 30.8 & 0.083 & 30.8 & 0.018 \\
\hline \multicolumn{5}{|c|}{ Severity of the impairments } \\
\hline None & 7.8 & & 3.9 & \\
\hline Temporary & 47.1 & & 26.5 & \\
\hline Permanent & 50.8 & $0.670 \dagger$ & 34.4 & $0.326 \dagger$ \\
\hline \multicolumn{5}{|c|}{ Degree of disability } \\
\hline None & 9.6 & & 3.0 & \\
\hline One & 51.1 & & 13.3 & \\
\hline Two & 61.1 & & 33.3 & \\
\hline Three & 55.6 & & 44.4 & \\
\hline Four & 40.0 & & 55.0 & \\
\hline Five & 52.2 & $0.775 \dagger$ & 56.5 & $0.001 \dagger$ \\
\hline
\end{tabular}

tp Value calculated after excluding the "none" category.
KEY POINTS

- The association of non-fatal war injuries with impairments, motor disabilities and physical independence is strongest for injuries of the lower limbs and abdomen.

- The need for medical and rehabilitative services is often underestimated in early routine relief efforts, because people disabled by war injuries are less likely to anticipate secondary and tertiary needs at the time of the injury.

- To minimise the development of secondary disabilities and poor social integration, research funds as well as services should tackle the broad and long term health and social needs of those injured and their families.

on reported disabilities was highest for difficulties in locomotion (37.6\%). In general, disabilities in personal selfcare such as eating, bathing and dressing were more likely to be reported for women than men, and the opposite was noticed for difficulties in locomotion. The impact of the injury on social roles was assessed for limitations in the major activity undertaken by students attending school and by those in the work force before the attack. Among students, $29.1 \%$ reported that they failed to continue their education as a result of their injuries, at the time of the survey, with $38 \%$ of these having acquired permanent impairment. Among working members, 41.6\% reported that they either lost their jobs or that they were unable to resume work, with around $34 \%$ of them having acquired permanent impairment.

To estimate the relation between body part affected and associated impairments and disabilities, sex and age adjusted risk ratios (RR) and their $95 \%$ confidence intervals (CI) were calculated (table 2). For impairments, the highest risk ratio was obtained for injuries to the lower limbs $(R R=1.62,95 \% C I=1.25$, $2.10)$, this was followed by injuries to the face $(\mathrm{RR}=1.45,95 \% \mathrm{CI}=1.11,1.89)$ and injuries to the abdomen $(\mathrm{RR}=1.18,95 \% \mathrm{CI}=0.71$, 1.97). Similarly, injuries to the lower limbs and to the abdomen increased the risk of motor disabilities by around threefold (95\% CI = $2.09,4.23)$ and 1.4 -fold $(95 \% \mathrm{CI}=0.87,2.29)$ respectively. For disabilities in personal selfcare, injuries to the abdomen $(\mathrm{RR}=1.88,95 \%$ $\mathrm{CI}=1.11,3.15)$ and to the lower limbs $(\mathrm{RR}=$ $2.13,95 \%$ CI $=1.39,3.27$ ) were also significantly associated with the outcome.

Thirty seven hospitals in the South, Nabatiyyeh, Beirut and Beqa'a attended to the injured people during the attack. The medical services included first aid, radiographs, medical tests, surgery and drugs. More than half of the injured had surgery and approximately half of this group were still under medical follow up. Despite these efforts, when asked about unmet needs, $66 \%$ of the persons who have been impaired, either permanently or temporarily, and $10 \%$ of those who were injured but not impaired reported the need for additional 
medical or rehabilitative services. Respondents were more likely to report the need for medical than for rehabilitative services, and this was consistent among both men and women, different age groups and different levels of impairments and disabilities (table 3). The proportion reporting the need for rehabilitative services increased consistently and significantly with the increase in the levels of disabilities $(p=0.001)$, a finding that was not noted for the need of medical services $(p=0.775)$.

\section{Discussion}

To date, the association of impairments and disabilities with non-fatal war related injuries and their long term impact have not been sufficiently investigated in the literature. Findings of the survey suggest that despite the efforts done on behalf the government, nongovernmental organisations and many others, the injury induced disability and its social and health consequences remain underestimated in routine relief efforts. The attack on Southern Lebanon, in April 1996, was sudden and acute in nature generating an epidemic of mass displacement. More than 400000 refugees, mostly women and children, were forced to evacuate their villages to more distant and safer areas, leaving behind a group of men in the productive age group at higher risk of exposure to injuries. ${ }^{78}$ Consequently, men represented a higher proportion of our study population than women, and the observed differences between men and women were more likely to represent differences in baseline characteristics of the population at risk during the attack period rather than differentials in risk of exposure to war injuries.

In conflict, the nature and severity of impairments and disabilities associated with the injury differ greatly from their peacetime counterparts. Several factors may contribute to prognosis and outcome. Evacuation time, access to timely and adequate medical resources, and strategies adopted to treat a potentially large number of severely wounded in an often short period of time affect the medical management of the injured. ${ }^{9-11}$ Almost half of our study population $(45.7 \%)$ was impaired and around $41 \%$ acquired one or more disability as a result of the Grapes of Wrath attack. In accordance with the literature,${ }^{12}$ injuries to the lower limbs were the most common site of injuries; consequently, difficulty in locomotion was the most common type of reported disability. The impact of the attack on social roles among students and economically active members has been substantial. Although injured women reported more disabilities for personal care than men did, no attempt was made to assess the impact of the attack on other social roles such as the domestic and care giving role of uninjured women. The majority of working men were labourers, both skilled (68\%) and unskilled (13.3\%), who depended largely on their physical abilities to perform their work. The lower income and unemployment consequences of disability are greater for people in the lower social classes where the level of income depends more on wages and overtime and is thus more directly related to physical capacity. ${ }^{13}$

Many of the impairments and disabilities were predictable consequences of a particular injury site. The impact of the injury was most severe for injuries to lower limbs and abdomen and results were, in general, in the expected direction. The failure to find a significant association between other sites of injuries with impairments and disabilities may reflect either reporting biases or differentials in selection of study population by injury site. Our study population excluded persons exposed to an injury with a fatal outcome. As injuries to the head, for example, were more likely to be fatal than those of the extremities, survivors of injuries to the head consisted mostly of a selective group with exposures milder than expected where associations with disabilities and impairments would be underestimated.

Given the nature of the study design and its setting, there are a number of other limitations. The study may have under-represented cases with mild injuries, in particular, those who were treated as outpatients. Another potential limitation lies in proxy reporting among the majority of study subjects. While the reliability and validity of information obtained could not be assessed, there were no differences in the reporting of impairments ( $\mathrm{p}$ value $=0.776$ ), disabilities ( $p$ value $=0.621$ ), or need for rehabilitative services $(p$ value $=0.986)$ between self and proxy respondents. However, a significantly higher proportion of the need for medical services was noted for self in comparison with proxy respondents $(33 \% v 22 \%)$. This only means that the results obtained could have been underestimates.

The findings of this study must be interpreted in light of the relative short period after the injury. At the time of the survey, the medical services offered to the injured were part of the usual first line acute treatment. The injured with newly acquired physical disabilities often require a multitude of services, such as further surgical interventions, prosthesis, physiotherapy, aids and devices such as wheelchairs, crutches and water mattresses, other rehabilitative work and vocational training, and finally psychological interventions to help them cope with their condition. The higher unmet need for medical than rehabilitative services may be explained by the self perception of "health" among newly injured people. The survey was conducted shortly after the attack when most of the seriously injured have not yet fully recovered physically from the war trauma, and when survival and "physical" health remain a priority. At such a time, respondents may not be able to anticipate secondary and tertiary needs such as schooling, vocational rehabilitation and other social and psychological support.

People with disabilities and chronic impairments require health care and social support that is significantly different from what they receive immediately after their injury. Anke and colleagues call for the need of individualised, 
multidisciplinary and continuous rehabilitation plans to optimise coping after severe multiple trauma. ${ }^{14}$ There is an increasing awareness of the poor fit between acute care mechanisms and the chronic and diverse health and social needs of people with disabilities and impairments. ${ }^{13}$ However, there remains a dearth of research that tackles the broad needs for care and support among people with war related injuries, ${ }^{41516}$ and there is a lack of understanding of how services, in the aftermath of a war trauma, can contribute to improvement of quality of life. These issues are better appraised in follow up studies that tackle the long term needs of those injured and their families. This should direct at avenues to minimise the development of secondary disabilities and poor social integration among old time neglected war victims.

Special thanks are extended to Drs Monique Chaaya and Cynthia Myntti for their review of the manuscript. Mr Abbas Husseini was responsible for most of the data collection in the field and his effort in tracing the study subjects is appreciated.

Funding: the study was financially supported by IMPACT/ Eastern Mediterranean Region (EMR). We wish to thank HRH Prince Abdul Aziz Bin Ahmed Al-Saoud, Chief of Board of IMPACT/EMR (Cyprus), and Dr Mohammad N Alamuddine for providing the funds and support to carry out the study. We for providing the funds and support to carry out the study. We
also thank the Ministry of Public Health in Lebanon and all non-governmental organisations who provided us with the list, including the names and addresses, of injured individuals.
Conflicts of interest: none.

1 Garfield RM, Neugut AI. Epidemiologic analysis of warfare. A historical review. $\mathcal{F} A M A$ 1991;266:688-92.

2 Toole MJ, Waldman RJ. Refugees and displaced persons. War, hunger, and public health. $\mathcal{F} A M A$ 1993;270:600-5.

3 Zwi A, Uglade A. Towards an epidemiology of political violence in the Third World. Soc Sci Med 1989;28:633-42.

4 Coupland RM. The effect of weapons on health. Lancet 1996;347:450-51.

5 World Health Organization. International classification of impairments, disabilities, and handicaps. A manual of classification relating to consequences of disease. Geneva: WHO, 1980.

6 StataCorp. Stata statistical software: release 4.0. College Station, TX: Stata Corporation, 1995.

7 Sibai AM, El Haji SS. The role of television in public health efforts in Lebanon. Lancet 1996;347:1269-70.

8 Kandela P. Medical response to operation Grapes of Wrath. Lancet 1996;347:1466-7.

9 Scott R. British military surgery, 1945-1985. F Trauma 1988;28:S83-5.

10 Fosse E, Husam H, Giannou C. The siege of Tripoli 1983. War surgery of Lebanon. $\mathcal{F}$ Trauma 1988;28:660-3.

11 Stong GC, Kalenian MH, Hope JW. Medical evacuation experiences of two 7th Corps medical companies supporting Desert Shield/Storm. Mil Med 1993;158:108-13.

12 Al-Harby. The evolving pattern of war-related injuries from the Afghanistan conflict. Mil Med 1996;161:163-4.

13 Kuh DJL, Wadsworth MEJ, Yusuf EJ. Burden of disability in a post war birth cohort in the UK. F Epidemiol Community Health 1994;48:262-9.

14 Anke AGW, Stanghelle JK, Finset A, et al. Long-term prevalence of impairments and disabilities for multiple trauma. $f$ Trauma 1997;42:54-61.

15 Andersson N, Palha da Sousa C, Paredes S. Social costs of land mines in four countries: Afghanistan, Bosnia, Cambodia, and Mozambique. BMf 1995;311:718-21.

16 Hermansson AC, Thyberg M, Timpka T. War-wounded refugees: the types of injury and influence of disability on well-being and social integration. Med Conflict Survival 1996;12:284-302. 